\title{
Expression of hepatocyte nuclear factor-1beta (HNF-1beta) in clear cell tumors and endometriosis of the ovary
}

\author{
Noriko Kato ${ }^{1}$, Shun-ichi Sasou ${ }^{2}$ and Teiichi Motoyama ${ }^{1}$ \\ ${ }^{1}$ Department of Pathology, Yamagata University School of Medicine, Yamagata, Japan and ${ }^{2}$ Department \\ of Pathology, Yamagata Prefectural Central Hospital, Yamagata, Japan
}

\begin{abstract}
Clear cell tumors of the ovary are frequently associated with ovarian endometriosis. Clinicopathologically, it has been suggested that clear cell tumors develop from endometriosis, but there has been little molecular evidence supporting this speculation. Microarray analysis revealed recently that hepatocyte nuclear factor1 beta (HNF-1beta) was significantly upregulated in clear cell carcinoma of the ovary. In the present study, we examined 30 clear cell tumors ( 26 malignant, three borderline, and one benign) and 40 endometriotic cysts to clarify if differentiation into the clear cell lineage already begins in ovarian endometriosis. All of the 30 clear cell tumors, including borderline and benign ones, showed immunohistochemical expression of HNF-1beta in the nucleus, while other types of ovarian epithelial tumors (endometrioid, serous, mucinous, and Brenner tumors) rarely expressed it. Among 30 clear cell tumors, 17 (56\%) cases were associated with endometriosis, and endometriotic epithelium was identified in 12 cases. In nine of the 12 cases, distinct nuclear immunostaining for HNF-1beta was detected in the endometriotic epithelium, as well as in the clear cell tumor. HNF-1beta expression was observed either in atypical endometriosis (four cases), or in endometriosis of a reactive nature (five cases). Furthermore, 16 of 40 (40\%) endometriotic cysts without a neoplasm also expressed HNF-1beta, and the expression was almost exclusively observed in the epithelium showing inflammatory atypia. Our results indicate that HNF-1beta is an excellent molecular marker for ovarian clear cell tumors, including benign, borderline and malignant lesions. Early differentiation into the clear cell lineage takes place in ovarian endometriosis, not only in atypical endometriosis, but also in endometriosis with degenerative and regenerative changes, and this is probably responsible for the frequent occurrence of clear cell carcinoma in ovarian endometriosis.
\end{abstract}

Modern Pathology (2006) 19, 83-89. doi:10.1038/modpathol.3800492; published online 16 September 2005

Keywords: ovary; clear cell tumor; endometriosis; hepatocyte nuclear factor-1beta; histogenesis

Among malignant epithelial tumors of the ovary, clear cell carcinomas, as well as endometrioid adenocarcinomas, are most frequently associated with ovarian endometriosis. The frequency of endometriosis is reportedly between 21 and $54 \%$ in large series of clear cell carcinomas. ${ }^{1-5}$ In addition, an atypical glandular change in endometriosis, the socalled atypical endometriosis, is often present associated with clear cell carcinomas, while it is rare in endometriosis without a neoplasm..$^{2,6,7}$ Thus, many clinicopathological studies have strongly suggested a malignant transformation of endometriosis to clear cell carcinomas, but little molecular

Correspondence: Dr N Kato, MD, Department of Pathology, Yamagata University School of Medicine, 2-2-2 Iida-Nishi, Yamagata 990-9585, Japan.

E-mail: nkato@med.id.yamagata-u.ac.jp

Received 13 June 2005; revised and accepted 9 August 2005; published online 16 September 2005 evidence exists to support the notion that endometriosis is the precursor of clear cell carcinomas. A molecular genetic study showed that ovarian endometriosis and its adjacent carcinoma shared a common allelotype; however, few clear cell carcinomas were subjected to this study. ${ }^{8}$ Recently, a study using an oligonucleotide array technique demonstrated that the expression of hepatocyte nuclear factor-1beta (HNF-1beta) was significantly upregulated in ovarian clear cell carcinoma cell lines, whereas non-clear cell carcinoma cell lines rarely expressed this protein. ${ }^{9} \mathrm{HNF}-1$ beta seems to be a useful molecular marker for ovarian clear cell carcinomas and also to be useful for clarifying the histogenesis of clear cell carcinoma.

In the present study, we investigated HNF-1beta expression in 30 ovarian clear cell tumors, including benign and borderline lesions, to evaluate whether HNF-1beta is a common marker for tumors showing clear cell differentiation. Expression of HNF-1beta 
was further analyzed in ovarian endometriosis, with or without clear cell tumors, to examine whether transformation into the clear cell lineage already takes place in endometriosis.

\section{Materials and methods}

\section{Materials}

We investigated 30 clear cell tumors of the ovary that had been surgically resected. The patients' ages ranged from 32 to 79 years (mean, 52.3 years). Tumor size varied from 4 to $17 \mathrm{~cm}$ (median, $11 \mathrm{~cm}$ ). A total of 2-11 (average, 5) slides were examined for each case. Their detailed histology was as follows: 26 clear cell carcinomas, three clear cell borderline tumors (one with microinvasion, one with minor foci of clear cell carcinoma, and one pure borderline tumor), and one clear cell adenofibroma. Diagnostic criteria for borderline tumor and adenofibroma was as follows: the borderline tumor shows atypical or even carcinomatous epithelium without invasion or just with microinvasion (one focus or more $10 \mathrm{~mm}^{2}$ or less in area), and the adenofibroma contains only benign-appearing glandular epithelium. ${ }^{10-12}$ One of the three clear cell borderline tumors contained atypical epithelium equivalent to intraepithelial carcinoma in approximately one-fourth of the epithelial component. Four of 26 clear cell carcinomas were also associated with an adenofibromatous or borderline area. Of 26 clear cell carcinomas, 22 were stage I, one tumor was stage II, and three were stage III, according to the criteria of International Federation of Gynecology and Obstetrics (FIGO). ${ }^{13}$ Of 30 clear cell tumors, 17 (56\%) were associated with endometriosis, defined as the presence of glandular epithelium accompanied by endometrial stroma, and/or hemorrhagic stroma or histiocytes containing hemosiderin within a thick fibrous wall. Glandular epithelium of endometriosis was identified in 12 cases, among which four $(13 \%)$ cases showed atypical endometriosis in some parts, diagnosed based on the histological features previously enumerated by Czernobilsky and Morris ${ }^{6}$ and LeGrenade and Silverberg. ${ }^{7}$ These features included large hyperchromatic or pale nuclei with moderate to marked pleomorphism; increased nuclear to cytoplasmic ratio; and cellular crowding, stratification or tufting. ${ }^{6,7}$ Endometriosis of a reactive nature also showed nuclear hyperchromatism or pleomorphism, but it was distinguished from atypical endometriosis based on the criteria of LeGrenade and Silverberg: endometriotic epithelium showing reactive atypia was still one layer thick, and was associated with severe subepithelial inflammation, which was rare in atypical endometriosis. ${ }^{7}$ For a comparative study, 40 ovarian endometriotic cysts containing glandular epithelium that were obtained from salpingo-oophorectomy or laparotomy, and 54 ovarian non-clear cell tumors, including 20 endometrioid adenocarcinomas, 15 serous tumors (eight malignant including four high-grade and four lowgrade, and seven borderline), 15 mucinous tumors (eight malignant and seven borderline), and four benign Brenner tumors, all of which were obtained from surgery, were investigated. Seven of 20 (35\%) endometrioid adenocarcinomas were associated with endometriosis, which was indicated by hemorrhagic stroma or histiocytes containing hemosiderin within a thick fibrous wall. All of the materials were fixed in formalin and embedded in paraffin.

\section{Immunohistochemistry}

Immunohistochemistry was performed on paraffinembedded tissue sections. A goat polyclonal antibody raised against a peptide mapping at the carboxy terminus of HNF-1beta of human origin (sc-7411; dilution 1/400; Santa Cruz Biotechnology, CA, USA) was used. Before the immunoperoxidase staining, the slides were pretreated with microwave heating at $95^{\circ} \mathrm{C}$ for $21 \mathrm{~min}$ in sodium citrate buffer (10 mM sodium-citrate monohydrate, pH6.0). Then the slides were incubated with anti-HNF1beta antibody at $4^{\circ} \mathrm{C}$ overnight. The immunohistochemical reactions were visualized using the streptavidin-biotin (SAB) complex system (Nichirei, Tokyo, Japan) with diaminobenzidine as a chromogen. The reactions were performed manually by hand. The results were scored on the basis of the percentage of nuclei positive for HNF-1beta ( 0 , no positive cells; $1,1-10 \% ; 2,11-30 \% ; 3,31-60 \%$; $4,>61 \%$ positive cells). The Fisher's exact test was used to analyze the statistical significance of the relationship between HNF-1beta expression and the clinicopathological variables. Differences were considered significant if $P$-values were less than 0.05 .

\section{Results}

\section{HNF-1beta in Clear Cell Tumors and Associated Endometriosis}

All of the 30 clear cell tumors showed strong nuclear immunostaining for HNF-1beta (Table 1, Figure 1). The nuclear immunostaining score was 4 in $15(50 \%)$ cases, 3 in seven $(23 \%)$ cases, 2 in six $(20 \%)$ cases, and 1 in two $(7 \%)$ cases. The different HNF-1beta expression patterns, that is, high (4 or 3 ) or low (2 or 1) score, did not correlate with patient age ( $<60$ or $\geq 60$ years, $P=0.35$ ), tumor size ( $<10 \mathrm{~cm}$ or $\geq 10 \mathrm{~cm}, P=0.36$ ), or FIGO stage (I/II or III, $P=0.19$ ). Also, there was no significant difference between the HNF-1beta score for clear cell tumors with endometriosis (17 cases) and that for clear cell tumors without endometriosis (13 cases) $(P=0.24)$. Among 12 clear cell tumors in which endometriotic epithelium was identified, nine cases showed distinct nuclear staining for 

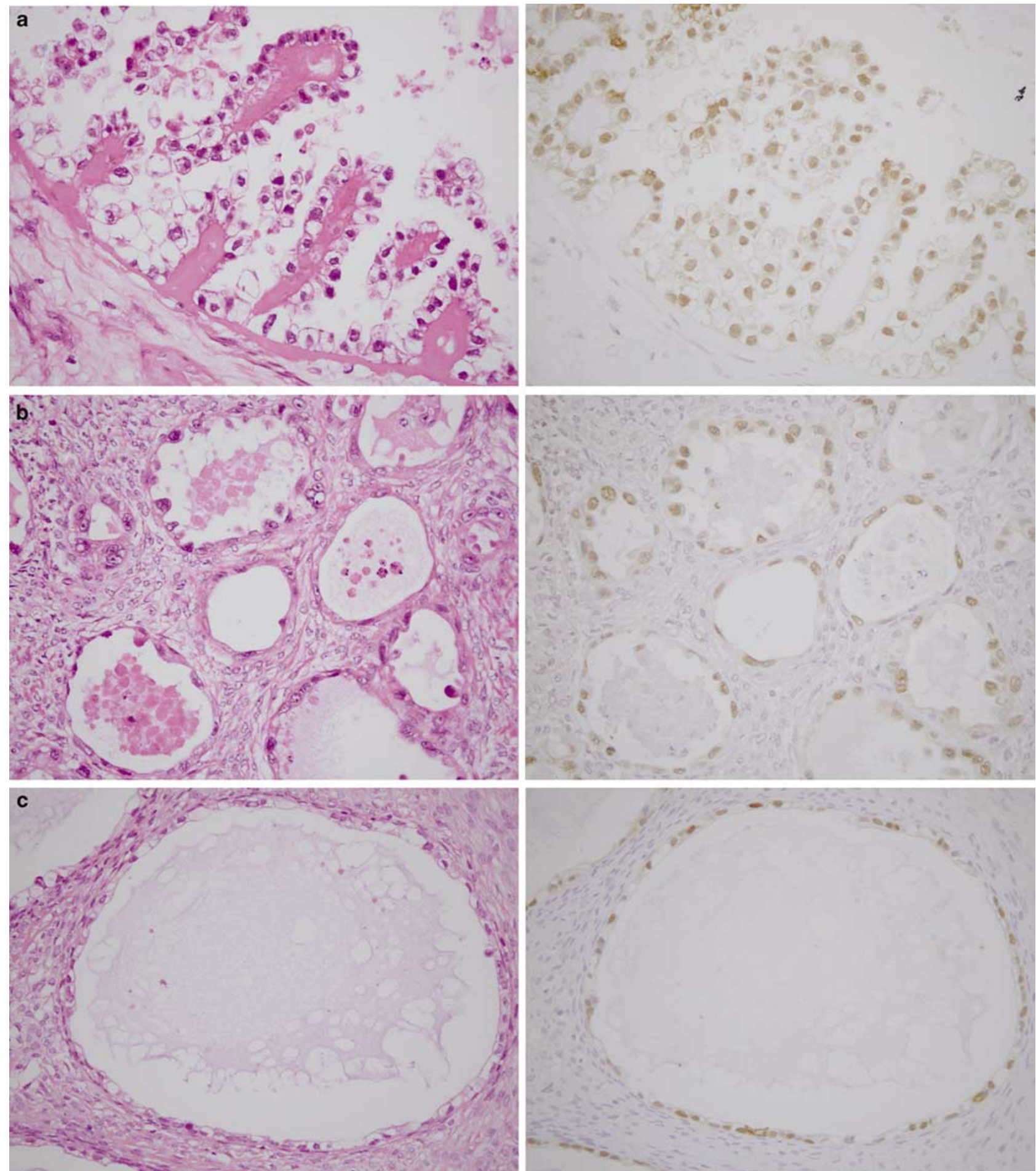

Figure 1 HNF-1beta expression in ovarian clear cell tumors. Clear cell carcinoma (a), clear cell borderline tumor (b), and clear cell adenofibroma (c) showed distinct nuclear staining for HNF-1beta in the neoplastic glandular epithelium. Original magnification: $\times 40$.

HNF-1beta in the endometriotic epithelium (Table 2). The epithelium showing HNF-1beta expression was that of atypical endometriosis in four cases (Figure 2a), while it was that of endometriosis showing inflammatory atypia in five cases (Figure 2b). Eosinophilic, hobnail, and ciliated cell meta- plasias of the endometriotic epithelium were observed in five, three, and two cases, respectively. The epithelium showing eosinophilic or hobnail metaplasia expressed HNF-1beta, whereas that showing ciliated cell metaplasia did not express it (Figure 2c). 
Table 1 Expression of hepatocyte nuclear factor-1beta (HNF1beta) in clear cell tumors and non-clear cell tumors of the ovary

\begin{tabular}{|c|c|c|c|c|}
\hline \multirow[t]{2}{*}{ Histology } & \multirow[t]{2}{*}{ No. } & \multicolumn{3}{|c|}{$H N F-1$ beta expression ${ }^{a}$} \\
\hline & & $\begin{array}{c}\text { High } \\
\text { (score } 4 \\
\text { or } 3 \text { ) }\end{array}$ & $\begin{array}{c}\text { Low } \\
\text { (score } 2 \\
\text { or } 1 \text { ) }\end{array}$ & $\begin{array}{l}\text { Negative } \\
\text { (score } 0 \text { ) }\end{array}$ \\
\hline Clear cell tumor & 30 & 22 & 8 & 0 \\
\hline Malignant $\mathrm{b}^{\mathrm{b}}$ & 26 & 18 & 8 & 0 \\
\hline Borderline & 3 & 3 & 0 & 0 \\
\hline Benign & 1 & 1 & 0 & 0 \\
\hline \multicolumn{5}{|c|}{ Non-clear cell tumor } \\
\hline Endometrioid & 20 & 0 & 0 & 20 \\
\hline Serous & 15 & 0 & 0 & 15 \\
\hline Mucinous & 15 & 0 & $4^{\mathrm{c}}$ & 11 \\
\hline Brenner & 4 & 0 & 0 & 4 \\
\hline
\end{tabular}

${ }^{\text {a }}$ Score $4,>60 \%$; score $3,31-60 \%$; score $2,11-30 \%$; score $1,<10 \%$ of tumor nuclei are positive for HNF-1beta.

${ }^{b}$ Four of 26 clear cell carcinomas were also associated with a small area of borderline and/or benign lesions.

${ }^{\mathrm{c}}<5 \%$ of cells showed expression.

Table 2 Expression of HNF-1beta in endometriosis

\begin{tabular}{lcc}
\hline Histology & No. of total cases & $\begin{array}{c}\text { No. of HNF-1beta- } \\
\text { positive cases }\end{array}$ \\
\hline $\begin{array}{l}\text { Clear cell tumor } \\
\text { With endometriosis }\end{array}$ & 30 & \\
$\begin{array}{l}\text { With endometriotic } \\
\text { epithelium }\end{array}$ & $12\left(4^{\mathrm{a}}\right)$ & $9\left(4^{\mathrm{a}}\right)$ \\
Endometriotic cyst & $40\left(0^{\mathrm{a}}\right)$ & $16\left(0^{\mathrm{a}}\right)$ \\
\hline
\end{tabular}

${ }^{\mathrm{a}}$ Atypical endometriosis.

HNF-1beta in Endometriotic Cysts without a Neoplasm

Most of the epithelium of endometriotic cysts was negative for nuclear staining for HNF-1beta. However, epithelium of a reactive nature, which was focally detected in 16 of $40(40 \%)$ cases, showed distinct nuclear staining for HNF-1beta. No foci of atypical endometriosis were identified in any of the 40 endometriotic cysts examined (Table 2).

\section{HNF-1beta in Other Types of Ovarian Epithelial Tumors}

None of the 20 endometrioid adenocarcinomas, 15 serous tumors, nor four Brenner tumors showed nuclear staining for HNF-1beta, although focal, faint cytoplasmic staining was observed in a few cases. Four of 15 (26\%) mucinous tumors (two malignant and two borderline) contained cells showing nuclear staining for HNF-1beta, but they accounted for no more than $5 \%$ of the total cells (Table 1).

\section{Discussion}

Clear cell tumors of the ovary are frequently associated with ovarian endometriosis ${ }^{1-5,10,11}$ : the frequency was reportedly as high as $54 \%$ in a large series of clear cell carcinomas ${ }^{2}$ and $33 \%$ in borderline and benign clear cell tumors. ${ }^{11}$ It has been strongly suggested that clear cell tumors develop from endometriosis, although an additional pathway may involve a progression sequence from clear cell adenofibroma to borderline tumor to carcinoma. Early transformation into the clear cell lineage possibly begins in the glandular epithelium of endometriosis. In the past, however, it was difficult to verify the above possibility because markers specific to clear cell tumors had not been established. Recently, progress in genome-wide microarray analysis led to the identification of several genes involved in ovarian clear cell carcinomas, including the genes for osteopontin (SPP1), nicotinamide $N$-methyltransferase, HNF-1beta (TCF2), RAB9, and lipopolysaccharide-induced tumor necrosis factor-alfa factor (PIG7).9,14 In particular, upregulated HNF-1beta expression at the protein level was very tightly linked to ovarian clear cell carcinomas, regardless of clinical stage or histological differentiation. ${ }^{9}$ Thus, HNF-1beta might be a useful molecular marker for analyzing histogenesis of ovarian clear cell tumors.

In the present study, we first examined whether HNF-1beta is expressed not only in clear cell carcinomas, but also in borderline and benign clear cell tumor lesions, which are often encountered in the company of clear cell carcinomas. ${ }^{10-12}$ Among 30 clear cell tumors examined, three were diagnosed as clear cell borderline tumor (one was a pure borderline tumor, and the other two were associated with microinvasion, and small foci of typical clear cell carcinoma, respectively), and one as pure clear cell adenofibroma. In addition, four of 26 clear cell carcinomas were associated with a minor area of adenofibroma and/or borderline lesion. Immunohistochemically, all four borderline and benign tumors, as well as clear cell carcinomas, showed distinct nuclear staining for HNF-1beta in the neoplastic glandular epithelium. In all of these cases, more than $60 \%$ of tumor cells were positive for HNF-1beta. The minor area of benign and/or borderline lesions that accompanied four cases of clear cell carcinoma was also positive for this protein. In contrast, none of the endometrioid, serous, nor Brenner tumors of the ovary expressed HNF-1beta. Approximately $25 \%$ of ovarian mucinous tumors contained cells expressing this protein, but the extent of such cells was no more than $5 \%$ of the total cells. These results indicate that HNF-1beta is a fairly specific marker for ovarian clear cell tumors, regardless of whether they are benign, bordeline or malignant lesions.

We subsequently focused on HNF-1beta expression in the epithelium of endometriosis adjacent to clear cell tumors to clarify whether transformation into clear cell lineage already occurs there. In the current series, 17 of $30(56 \%)$ clear cell tumors were associated with endometriosis, and glandular 

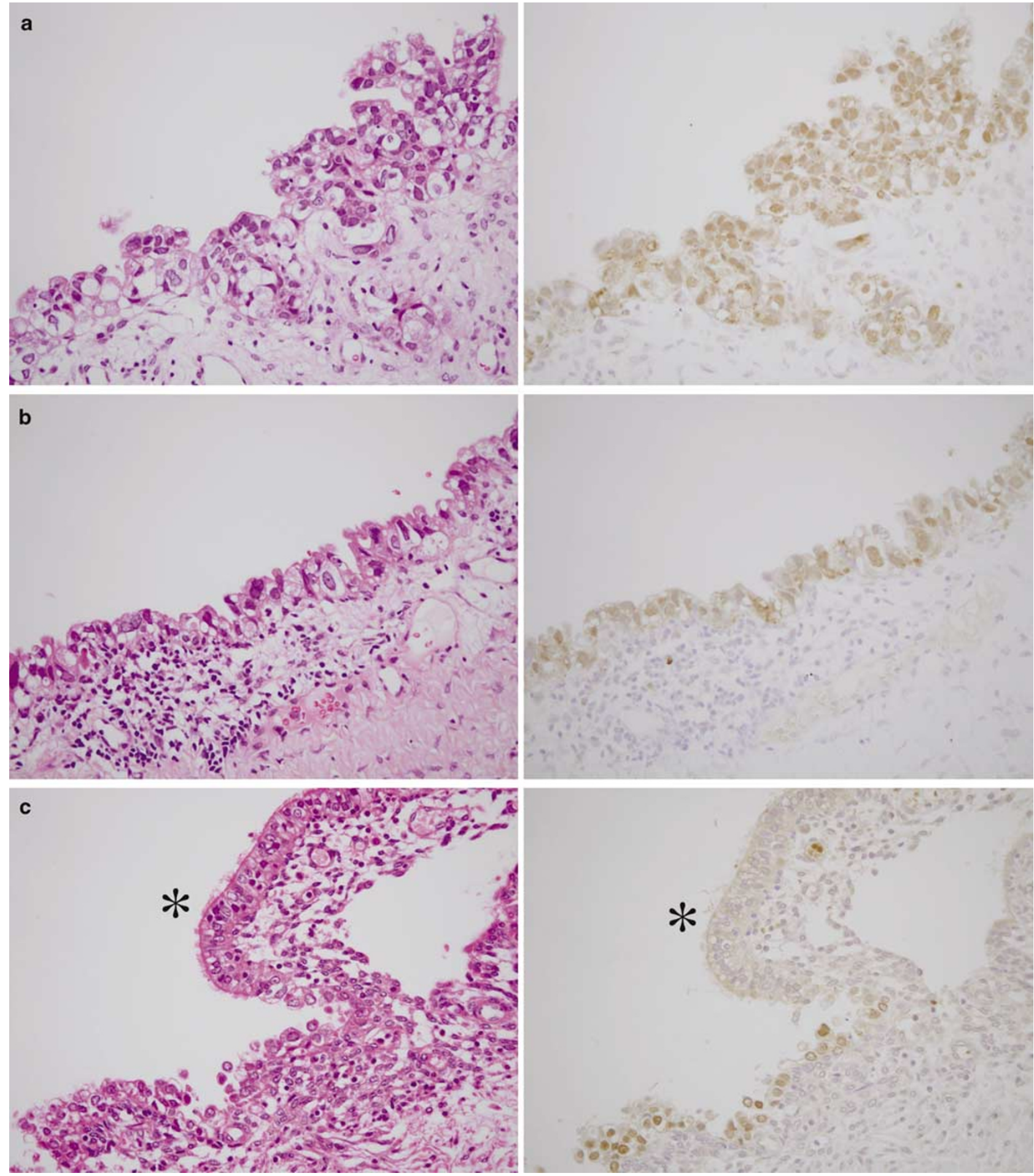

Figure 2 HNF-1beta expression in ovarian endometriosis. Atypical endometriosis (a), which was found to be close to clear cell carcinoma, showed strong HNF-1beta expression in the nucleus. Endometriotic epithelium showing inflammatory atypia (b, c) also showed strong nuclear staining for HNF-1beta, but that showing ciliated cell metaplasia (c, asterisks) did not express this protein. Original magnification: $\times 40$.

epithelium was identified in 12 of these 17 cases, including atypical endometriosis in four cases. Distinct nuclear staining for HNF-1beta was observed in nine of the 12 cases: four in atypical endometriosis and five in endometriosis of a reactive nature, characterized by one layer of cuboidal or flattened cells showing inflammatory atypia in association with stromal inflammation, epithelial denudation or regeneration. ${ }^{6,7}$ Furthermore, HNF-1beta expression was also detected in 16 
of $40(40 \%)$ cases of endometriosis without clear cell tumors, where it was almost exclusively detected in the epithelium showing inflammatory atypia. These findings indicate that some epithelial cells of ovarian endometriosis, not only of atypical endometriosis but also of endometriosis that undergoes repeated regenerative and inflammatory changes, have already acquired a clear cell phenotype, although we could not completely eliminate a possibility that some of reactive atypia may really represent an early form of true atypia which might not be entirely recognizable at the histological levels. In either case, clonal expansion of such cells is probably responsible for the development of clear cell carcinoma in ovarian endometriosis.

Endometrioid adenocarcinoma, as well as clear cell carcinoma, is frequently associated with ovarian endometriosis and likely to arise from endometriosis. $^{1-3}$ In the current series, seven of 20 (35\%) endometrioid adenocarcinomas contained hemorrhagic stroma or hemosiderin-laden histiocytes within a thick fibrous wall, which indicates an association of endometriosis. Endometriotic epithlium, however, was not identified in any of these cases. Further study is needed to evaluate whether or not HNF-1beta is expressed in endometriosis/atypical endometriosis that is associated with ipsilateral endometrioid adenocarcinoma. As for HNF-1beta expression in endometrioid adenocarcinoma, none of the 20 cases examined were positive for HNF1beta, which was concordant with a previous study. ${ }^{9}$ There is a possibility that endometrioid adenocarcinomas, in contrast to clear cell carcinomas, derive from epithelial cells of endometriosis which are free from HNF-1beta expression. Further investigation of this protein in ovarian endometriosis might explicate the reason why some endometriosis develop into clear cell carcinoma, while others evolve into endometrioid adenocarcinoma.

In ovarian endometriosis, especially in that associated with a neoplasm, metaplastic changes are often observed: eosinophilic metaplasia is the most common, followed by ciliated cell, hobnail and mucinous metaplasias. Papillary, squamous and clear cell metaplasias are rare.$^{15}$ In the current series, none of the cases of endometriosis, regardless of the HNF-1beta positivity, showed clear cell metaplasia. This indicates that the expression of HNF-1beta, by itself, is not coupled with a morphological change into clear cells. Eosinophilic, hobnail, and ciliated cell metaplasias were observed in five, three, and two cases, respectively, among 12 cases of epithelium-preserved endometriosis with clear cell tumor. Interestingly, epithelium showing eosinophilic metaplasia, as well as that showing hobnail metaplasia, was positive for HNF-1beta, whereas epithelium showing ciliated cell metaplasia never expressed this protein. It is speculated that eosinophilic or hobnail metaplasia in endometriosis is more closely related to the development of clear cell tumor than is ciliated cell metaplasia.
The role of HNF-1beta expression in ovarian clear cell tumors and endometriosis remains unclear. HNF-1beta is a transcription activator that regulates the promoters or enhancers of genes that are expressed in a liver-specific manner, such as albumin and alpha-fetoprotein. ${ }^{16-18}$ In normal tissue, HNF-1beta is expressed not only in the liver, but also in the digestive tract, pancreas, and kidney, where it plays a role as a major regulator of glucose homeostasis. ${ }^{19}$ It has been shown that the reduction of HNF-1beta expression by RNA interference induced apoptosis in ovarian clear cell carcinoma cell lines, suggesting that HNF-1beta expression is essential for the survival of clear cell carcinoma cells. ${ }^{9}$ HNF-1beta might directly or indirectly regulate unknown target genes relevant to cell death. In general, endometriosis is associated with a decrease in the number of cells undergoing apoptosis. ${ }^{20}$ Overexpression of HNF-1beta might enable endometriotic epithelium to acquire resistance to apoptosis and subsequently to develop neoplasms, especially clear cell carcinomas. To date, patients with clear cell carcinoma have a significantly worse prognosis than patients with non-clear cell carcinomas, because of their low response to standard platinum-based chemotherapy. ${ }^{21} \mathrm{HNF}$-1beta might be a specific molecular target for therapy of ovarian clear cell carcinomas in the future.

In conclusion, HNF-1beta is a molecular marker for ovarian clear cell tumors, including benign, borderline, and malignant lesions. HNF-1beta is also expressed in ovarian endometriosis of atypical type or of a reactive nature. Early differentiation into the clear cell lineage takes place in the endometriotic epithelium, and clonal expansion of such cells is probably responsible for the development of clear cell carcinoma of the ovary.

\section{References}

1 Vercellini P, Parazzini F, Bolis G, et al. Endometriosis and ovarian cancer. Am J Obstet Gynecol 1993;169: 181-182.

2 Fukunaga M, Nomura K, Ishikawa E, et al. Ovarian atypical endometriosis: its close association with malignant epithelial tumours. Histopathology 1997;30: 249-255.

3 Sainz de la Cuesta R, Eichhorn JH, Rice LW, et al. Histologic transformation of benign endometriosis to early epithelial ovarian cancer. Gynecol Oncol 1996; 60:238-244.

4 Montag AG, Jenison EL, Griffiths CT, et al. Ovarian clear cell carcinoma. A clinicopathologic analysis of 44 cases. Int J Gynecol Pathol 1989;8:85-96.

5 Crozier MA, Copeland LJ, Silva EG, et al. Clear cell carcinoma of the ovary: a study of 59 cases. Gynecol Oncol 1989;35:199-203.

6 Czernobilsky B, Morris WJ. A histologic study of ovarian endometriosis with emphasis on hyperplastic and atypical changes. Obstet Gynecol 1979;53: 318-323. 
7 LaGrenade A, Silverberg S. Ovarian tumors associated atypical endometriosis. Hum Pathol 1988;19:1080-1084.

8 Jiang X, Morland SJ, Hitchcock A, et al. Allelotyping of endometriosis with adjacent ovarian carcinoma reveals evidence of a common lineage. Cancer Res 1998;58: 1707-1712.

9 Tsuchiya A, Sakamoto M, Yasuda J, et al. Expression profiling in ovarian clear cell carcinoma. Identification of hepatocyte nuclear factor-1 beta as a molecular marker and a possible molecular target for therapy of ovarian clear cell carcinoma. Am J Pathol 2003;163: 2503-2512.

10 Roth LM, Langley FA, Fox H, et al. Ovarian clear cell adenofibromatous tumors. Benign, of low malignant potential, and associated with invasive clear cell carcinoma. Cancer 1984;53:1156-1163.

11 Bell DA, Scully RE. Benign and borderline clear cell adenofibromas of the ovary. Cancer 1985;56: 2922-2931.

12 Prat J (ed). Pathology of the Ovary. Saunders: Philadelphia, 2004, pp 154-155.

13 Benedet JL, Bender H, Jones III HW, et al. FIGO staging classifications and clinical practice guidelines in the management of gynecologic cancers. FIGO committee on Gynecologic Oncology. Int J Gynaecol Obstet 2000; 70:209-262.

14 Schwartz DR, Kardia SL, Shedden KA, et al. Gene expression in ovarian cancer reflects both morphology and biological behavior, distinguishing clear cell from other poor-prognosis ovarian carcinomas. Cancer Res 2002;62:4722-4729.

15 Fukunaga M, Ushigome S. Epithelial metaplastic changes in ovarian endometriosis. Mod Pathol 1998; 11:784-788.

16 Courtois G, Baumhueter S, Crabtree GR. Purified hepatocyte nuclear factor 1 interacts with a family of hepatocyte-specific promoters. Proc Natl Acad Sci USA 1988;85:7937-7941.

17 Cereghini S, Blumenfeld M, Yaniv M. A liver-specific factor essential for albumin transcription differs between differentiated and dedifferentiated rat hepatoma cells. Genes Dev 1988;2:957-974.

18 Rey-Campos J, Chouard T, Yaniv M, et al. vHNF1 is a homeoprotein that activates transcription and forms heterodimers with HNF1. EMBO J 1991;10:1445-1457.

19 Pontoglio M. Hepatocyte nuclear factor 1, a transcription factor at the crossroads of glucose homeostasis. J Am Soc Nephrol 2000;11:S140-S143.

20 Swiersz LM. Role of endometriosis in cancer and tumor development. Ann NY Acad Sci 2002;955: 281-292.

21 Goff BA, Sainz de la Cuesta R, Muntz HG, et al. Clear cell carcinoma of the ovary: a distinct histologic type with poor prognosis and resistance to platinum-based chemotherapy in stage III disease. Gynecol Oncol 1996;60:412-417. 